\title{
Prolactin and gonadotrophin changes following generalised and partial seizures
}

\author{
J DANA-HAERI, ${ }^{*} \dagger$ MR TRIMBLE, ${ }^{*}$ J OXLEY $\dagger$ \\ From the Institute of Neurology, University of London* and Chalfont Centre for Epilepsy, Chalfont St Peter, \\ Bucks, $\dagger U K$
}

SUMMARY Postictal values of prolactin, LH and FSH have been recorded in patients with both generalised tonic-clonic and partial seizures. Elevations of prolactin and LH were seen immediately and at 20 minutes in males and females with generalised attacks. At sixty minutes values for prolactin had fallen to baseline levels, but LH remained elevated. FSH values were increased in females only, at twenty and sixty minutes. Following partial seizures prolactin was elevated, especially with complex partial seizures, at twenty minutes. These results are discussed in the light of known electrophysiological mechanisms relating to partial seizures, and clinical guidelines for the use of neurohormonal tests in the evaluation of seizures are suggested.

To-date most information concerning endocrine changes following seizures derives from studies of electrochemically induced attacks in animals, and from electroconvulsive therapy (ECT) in patients. In rats, direct electrical stimulation of the medial basal hypothalamus has been shown to increase plasma prolactin levels. ${ }^{1}$ In humans, Ohman et $a l^{2}$ first reported that ECT led to increases of serum prolactin in patients with endngenous depression, findings later confirmed by O'Dea $e a^{3}$ and Trimble. ${ }^{4}$ Arato et $a l^{5}$ noted similar findings following ECT in schizophrenia.

Several investigators have now reported serum prolactin changes following epileptic seizures in patients. Trimble ${ }^{4}$ in a study of nine patients with generalised epilepsy found prolactin levels to rise sharply after the ictus. Since similar rises were noted following unilateral ECT with anaesthesia and muscle relaxation, it was concluded that the changes were consequent on the epileptic activity itself. Abbott $e t a l^{6}$ measured serum prolactin and cortisol levels in 26 patients after tonic-clonic seizures, and noted significant increases in both. In these studies, as in the recent reports from Hoppner et al ${ }^{7}$ and Collins et $a l,{ }^{8}$ prolactin elevation seems maximal 15

Address for reprint requests: Dr MR Trimble, The National Hospital for Nervous Diseases, Queen Square, London WC1N 3BG, UK.

Received 16 July 1982 and in revised form 3 November 1982 Accepted 20 November 1982 to 20 minutes after the seizures, and thereafter appears to decline towards baseline values.

There are less data regarding the effects of seizure activity on gonadotrophin release in man. Ryan et $a l^{9}$ measured levels of gonadotrophins, thyroid stimulating hormone, and growth hormone in men and post-menopausal women after ECT, and noted a significant rise in FSH and LH in some of the males. Vigas et $a l^{10}$ demonstrated a significant increase in serum LH levels after ECT in female psychiatric patients, although FSH was not affected.

In this study we report further data on changes of prolactin and gonadotrophins following a variety of seizure types in patients with epilepsy.

\section{Materials and methods}

Sixty-four patients with epilepsy (42 males and 22 females) who were resident at the Chalfont Centre for Epilepsy, Chalfont St Peter, England, were studied. All subjects were receiving polytherapy with combinations of anticonvulsant drugs. Blood samples were drawn immediately, twenty minutes and one hour following a patient's seizure. A description of the seizure pattern was recorded at the time of the attack by a member of the nursing staff experienced at observing patients with epilepsy and was written on a card which accompanied the blood samples taken in relationship to the seizure. In addition, no fewer than four blood samples were obtained over a period of two hours from each patient during seizure-free intervals to assess baseline hormonal levels.

Classification of the seizure type was made independently of the knowledge of serum hormonal levels, using the fit description cards by one author (MRT). A broad 
division into generalised and partial seizures was made, following the International Classification of Seizures. Partial seizures were then further subdivided into simple and complex groups. The main inclusion criterion for complex partial was an attack associated with alteration of consciousness.

Serum samples were separated and stored at $-20^{\circ} \mathrm{C}$ until assayed. Prolactin, LH and FSH were measured by specific radio-immunoassay techniques at St Bartholomew's Hospital laboratories. Antisera used were: rabbit anti-prolactin (P4-577), rabbit anti-LH (LHF/87) and rabbit anti-FSH (FSHM 93). Standards were assayed against MRC 71/222, MRC 68/40, and MRC 68/104. The normal baseline values, using these methods are: for prolactin 100-360 mu/l; for LH and FSH in males, 1.4-9.7 and $0 \cdot 8-7 \cdot 0 \mathrm{u} / \mathrm{l}$ respectively; and early follicular levels of LH and FSH in females, 2.4-14.1 u/l and 1.5-11.2 u/l respectively. In the analysis of data, results were evaluated by the Mann-Whitney U-test.

\section{Results}

The baseline and post-ictal levels of the hormones are shown in tables 1 and 2 . The serum prolactin and LH levels following generalised seizures (tonicclonic) were increased immediately and at twenty minutes in both male and female patients (table 1). Prolactin levels returned to near baseline levels by 60 minutes, although $\mathrm{LH}$ values remained elevated at this time. One of the male patients failed to show a rise in prolactin. Sixteen of the $27(59 \%)$ showed serum prolactin rises to greater than $1000 \mathrm{mu} / \mathrm{l}$ after

Table 1 Median levels and ranges of prolactin, LH, and FSH in 15 male and 12 female patients after tonic-clonic seizures compared with their baseline levels

\begin{tabular}{|c|c|c|c|c|c|c|}
\hline & \multicolumn{3}{|c|}{ Male patients $(n=15)$} & \multicolumn{3}{|c|}{ Female patients $(n=12)$} \\
\hline & Prolactin mu/l & $L H u / l$ & $F S H u / l$ & Prolactin mu/l & $L H u / l$ & $F S H u / l$ \\
\hline $\begin{array}{l}\text { Baseline } \\
<1 \mathrm{~min} \\
20 \mathrm{~min} \\
60 \mathrm{~min}\end{array}$ & $\begin{array}{l}182 \cdot 5 \\
(118-540) \\
750 \cdot 0^{*} \\
(282-1850) \\
1104 \cdot 0^{*} \\
(100-2815) \\
396 \cdot 0 \\
(130-1470)\end{array}$ & $\begin{array}{l}6 \cdot 0 \\
(2 \cdot 5-15 \cdot 3) \\
14 \cdot 0^{*} \\
(4 \cdot 4-60 \cdot 0) \\
16 \cdot 5^{*} \\
(5 \cdot 2-72 \cdot 0) \\
15 \cdot 0^{*} \\
(4 \cdot 0-70 \cdot 0)\end{array}$ & $\begin{array}{l}3 \cdot 0 \\
(1 \cdot 3-14 \cdot 4) \\
3 \cdot 5 \\
(1 \cdot 2-12 \cdot 0) \\
4 \cdot 7 \\
(1 \cdot 4-14 \cdot 9) \\
5 \cdot 0 \\
(0 \cdot 5-13 \cdot 5)\end{array}$ & $\begin{array}{l}176 \cdot 0 \\
(110-287) \\
1475 \cdot 0^{*} \\
(195-2426) \\
1914 \cdot 5^{*} \\
(940-3273) \\
463 \cdot 0 \\
(180-1512)\end{array}$ & $\begin{array}{l}5 \cdot 3 \\
(3 \cdot 0-10 \cdot 0) \\
10 \cdot 2^{*} \\
(5 \cdot 0-13 \cdot 0) \\
14 \cdot 1^{*} \\
(4 \cdot 5-29 \cdot 0) \\
13 \cdot 0^{*} \\
(4 \cdot 0-45 \cdot 0)\end{array}$ & $\begin{array}{l}2 \cdot 8 \\
(1 \cdot 2-4 \cdot 0) \\
5 \cdot 0 \\
(1 \cdot 1-11 \cdot 6) \\
6 \cdot 3^{*} \\
(1 \cdot 5-12 \cdot 0) \\
6 \cdot 7^{*} \\
(1 \cdot 6-14 \cdot 5)\end{array}$ \\
\hline
\end{tabular}

*Mann-Whitney $U$ test $\mathrm{p}<0.01$ (comparison made with the baseline levels).

Table 2 Median levels and ranges of prolactin, LH, and FSH in 27 male and 10 female patients after partial attacks compared with their baseline levels

\begin{tabular}{|c|c|c|c|c|c|c|}
\hline & \multicolumn{3}{|c|}{ Male patients $(n=27)$} & \multicolumn{3}{|c|}{ Female patients $(n=10)$} \\
\hline & Prolactin mu/l & $L H u / l$ & $F S H u / l$ & Prolactin mu/l & $L H u / l$ & $F S H u / l$ \\
\hline $\begin{array}{l}\text { Baseline } \\
<1 \mathrm{~min} \\
20 \mathrm{~min} \\
60 \mathrm{~min}\end{array}$ & $\begin{array}{l}147 \cdot 5 \\
(88-464) \\
400 \cdot 0^{*} \\
(130-750) \\
660 \cdot 0^{*} \\
(185-1455) \\
268 \cdot 0 \\
(90-540)\end{array}$ & $\begin{array}{l}6 \cdot 0 \\
(1 \cdot 9-15 \cdot 0) \\
9 \cdot 0 \\
(2 \cdot 5-24 \cdot 7) \\
9 \cdot 5 \\
(2 \cdot 9-25 \cdot 5) \\
8 \cdot 5 \\
(3 \cdot 0-29 \cdot 0)\end{array}$ & $\begin{array}{l}2 \cdot 0 \\
(0 \cdot 4-8 \cdot 5) \\
3 \cdot 8 \\
(0 \cdot 9-27 \cdot 5) \\
4 \cdot 7 \\
(1 \cdot 0-31 \cdot 3) \\
4 \cdot 8 \\
(0 \cdot 5-25 \cdot 2)\end{array}$ & $\begin{array}{l}205 \cdot 0 \\
(130-258) \\
306 \cdot 5 \\
(140-1193) \\
768 \cdot 0^{*} \\
(210-1580) \\
217 \cdot 0 \\
(120-1216)\end{array}$ & $\begin{array}{l}5 \cdot 9 \\
(3 \cdot 0-11 \cdot 0) \\
10 \cdot 0 \\
(3 \cdot 0-63 \cdot 6) \\
14 \cdot 0^{*} \\
(3 \cdot 0-67 \cdot 2) \\
11.5 \\
(4 \cdot 0-85 \cdot 5)\end{array}$ & $\begin{array}{l}3 \cdot 2 \\
(1 \cdot 2-4 \cdot 6) \\
2 \cdot 8 \\
(0 \cdot 5-10 \cdot 2) \\
3 \cdot 15 \\
(1 \cdot 5-12 \cdot 3) \\
2 \cdot 4 \\
(1 \cdot 1-15 \cdot 5)\end{array}$ \\
\hline
\end{tabular}

*Mann-Whitney $U$ test $\mathrm{p}<0.01$ (comparison with the baseline levels).

Table 3 The median and ranges of prolactin, LH, and FSH in 8 patients with simple partial seizures, and 18 patients with complex partial seizures

\begin{tabular}{|c|c|c|c|c|}
\hline & & Prolactin mu/l & $L H u / l$ & $F S H u / l$ \\
\hline \multirow[t]{2}{*}{ Simple seizure $(n=8)$} & Baseline & $172 \cdot 0$ & $6 \cdot 5$ & $\begin{array}{l}4 \cdot 0 \\
(0.5-8.5)\end{array}$ \\
\hline & $20 \mathrm{~min}$ & $\begin{array}{l}295 \cdot 0 \\
(207-868)\end{array}$ & $\begin{array}{l}7 \cdot 5 \\
(3 \cdot 0-25 \cdot 5)\end{array}$ & $\begin{array}{l}5 \cdot 4 \\
(1 \cdot 5-31 \cdot 3)\end{array}$ \\
\hline \multirow[t]{2}{*}{ Complex partial $(n=18)$} & Baseline & $\begin{array}{l}159 \cdot 5 \\
(88-254)\end{array}$ & $6 \cdot 2$ & $\begin{array}{l}2 \cdot 0 \\
(0.4-4 \cdot 2)\end{array}$ \\
\hline & $20 \mathrm{~min}$ & $\begin{array}{l}706 \cdot 5^{*} \\
(185-1455)\end{array}$ & $\begin{array}{l}10.7 \\
(2.9-46.5)\end{array}$ & $\begin{array}{l}4 \cdot 0 \\
(1 \cdot 0-12 \cdot 5)\end{array}$ \\
\hline
\end{tabular}

*Mann-Whitney $U$ test (comparison with the baseline levels). 

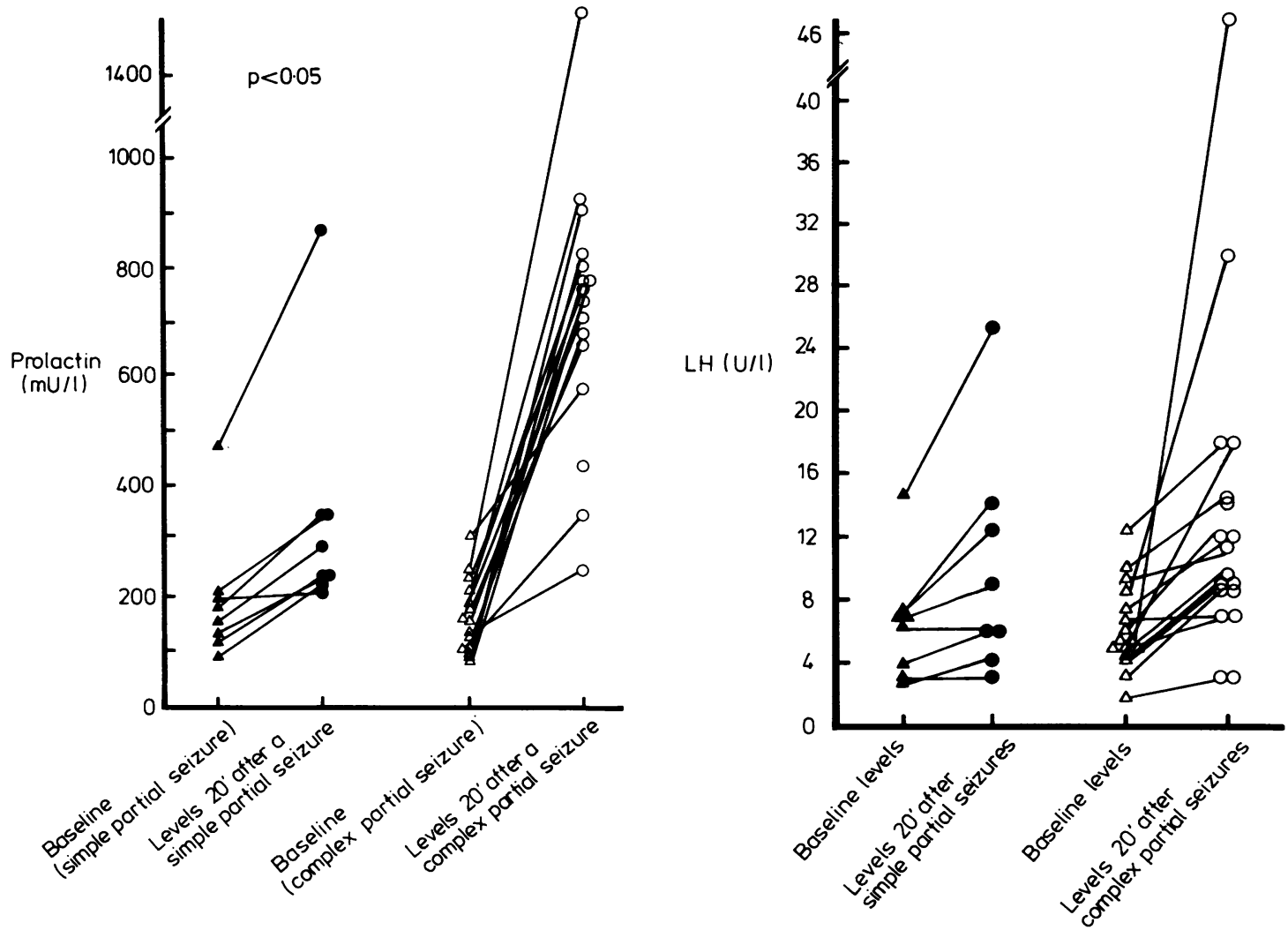

Fig 1 Prolactin and LH levels in patients with simple and complex partial seizures

a generalised seizure, and 26 out of 27 had increases to a level greater than $500 \mathrm{mu} / \mathrm{l}(96 \%)$. The FSH levels remained unchanged in male patients after tonic-clonic seizures, but rises were seen in the female patients lasting up to one hour.

Following partial seizures (table 2), a rise in prolactin was noted for male patients immediately and at 20 minutes after the attack, and for female patients at 20 minutes only. LH levels were increased at 20 minutes in females. No alteration of FSH levels was seen. The elevations in prolactin were less than noted for generalised seizures, and, in the male patients, $17(63 \%)$ had a rise to a greater level than $500 \mathrm{mu} / \mathrm{l}$ at 20 minutes.

Of the 37 patients with partial seizures, 18 had a clear alteration of consciousness associated with their attack, and eight had no change of consciousness. These were taken to form the two groups, namely complex and simple partial seizures respectively. When patients were thus subdivided (table 3 : figs $1 \& 2$ ) a rise in prolactin was seen to occur following complex partial seizures at 20 minutes.
The ratio of males to females in these two samples was: simple $6: 2$, complex $14: 4$. As shown in fig 1 only one patient classified as simple partial seizures increased prolactin levels to greater than $500 \mathrm{mu} / \mathrm{l}$, in contrast to $14(78 \%)$ of those with complex partial seizures. This one patient had elevated baseline values.

\section{Discussion}

The result of this study confirm the previous observation that serum prolactin increases following seizures, especially after generalised epilepsy with a tonic-clonic presentation. ${ }^{46}$ Maximum increases are seen at 15 to 20 minutes, although elevations are apparent immediately after the seizure has occurred. There is a return to baseline levels within 60 minutes. $\mathrm{LH}$ values also rise immediately and at 20 minutes, and in contrast to prolactin levels remain elevated one hour later. FSH changes are less constant being noted mainly in the female group.

In this study we have attempted to explore in 
more detail the changes in anterior pituitary hormone output following partial seizures. We show that prolactin and gonadatrophin levels change, especially in patients with complex symptomatology, as defined as alteration of consciousness associated with the partial attack. Prolactin changes are most clearly defined in these patients, although in some females $\mathrm{LH}$ alterations have also been recorded 20 minutes following the ictus.

The mechanism of these hormonal changes is still speculative. It is unlikely however to be a nonspecific stress response or one related to generalised neuromuscular activity. In the first instance, similar changes have been recorded following ECT with full neuromuscular relaxation; ${ }^{4}$ in addition similar anterior pituitary hormone changes have now been recorded in animal models of epilepsy, namely the photosensitive baboon Papio papio. ${ }^{11}$ Finally Abbott et al, ${ }^{6}$ following assessment of prolactin and cortisol levels in simulated seizures, where only stress occurred, showed that serum cortisol levels increased while prolactin concentrations were unchanged. It is recognised that changes in prolactin have been recorded following generalised anaesthesia for major surgery, ${ }^{12}$ in some cases to the level of values recorded here postictally. The mechanism of such changes are not understood, and the contribution of anaesthetic agents, for example, is as yet undetermined. Nevertheless, prolonged loss of consciousness could be one factor. It seems most likely that the increases observed in our investigations are due to abnormal electrical activity within areas of the central nervous system that regulate anterior pituitary hormone release. This suggests that in generalised seizures, such activity leads to either suppression of prolactin inhibitory factor, or stimulation of the as yet unidentified prolactin stimulating hormone, thus leading to the observed serum changes. In that prolactin and LH are under the inhibitory control of dopamine which is synthesised by tubero-infundibular neurons in the arcuate and peri-ventricular nuclei of the medial basal hypothalamus, ${ }^{13}$ it is hypothesised that such nuclear groups may be involved in the generalised discharge.

Of particular interest, however, is the fact that following partial seizures, it is those patients with complex as opposed to simple partial seizures that show significant alterations in prolactin. This suggests that in those patients abnormal electrical activity is also affecting similar neuronal structures, leading to the increased serum prolactin levels. In that the origin of abnormal electrical activity in the majority of patients with complex partial seizures is from the temporal lobes, it is here suggested that seizure spread is occurring from medial temporal structures, such as the amygdala and the hippocam- pus, to the hypothalamic nuclei leading not only to the alteration of consciousness but also to changes in anterior pituitary hormone output. This is in keeping with the neurophysiological observations of, for example, Heath ${ }^{14}$ who demonstrated, using implanted electrodes in both animal models and humans with epilepsy, spread of seizure activity from medial temporal structures to forebrain limbic nuclei, and with the suggestion of Jasper ${ }^{15}$ that alteration of consciousness in patients with partial seizures requires bilateral abnormal electrical activity to be recorded. Of importance here is the distinction between simple and complex partial seizures based on alteration of consciousness. In the International Classification of $1969,{ }^{16}$ complex has no reference to alteration of consciousness and refers to higher cognitive function, generally suggesting alteration in activity in the so-called "interpretative cortex". ${ }^{17}$ In more recent revised editions of the Classification, ${ }^{18}$ complex has come to suggest alteration of consciousness. As noted here, this criterion may be distinguished on a neurohormonal basis since there is much less change of anterior pituitary hormone output following simple partial attacks. However, the alterations noted in complex partial seizures with regard to prolactin are similar to those recorded for generalised seizures, and suggest that if alteration of consciousness is to be used as a distinguishing feature for complex partial seizures, then when such clinical changes occur the attacks are not partial butcô have become generalised.

Another observation presented has been the elevated levels of prolactin and $\mathrm{LH}$ that are seen immediately following generalised seizures, and for partial seizures in males. This might indicate that before the appearance of the clinical attack, and presumably alteration of the surface electroencephalogram which occurs at the onset of clinical seizures, spread of abnormal electrical activity has already occurred in deeper structures thus leading to hormonal release. Again this is compatible with the observations of Heath ${ }^{14}$ where abnormal recordings from subcortical sites, especially from the hippocampus and amygdala are noted in epileptic patients with deep electrode implantation prior to the clinical seizures. In order to explore the relationship between neurohormonal changes and electroencephalographic changes further, investigations with video-telemetry, and preferably with intracortically implanted electrodes will be required.

From the clinical point of view one of the more important sequelae of these investigations has been to further analyse the value of measurements of anterior pituitary hormones following seizures in differential diagnosis. In an earlier paper ${ }^{4}$ it was suggested that patients with non-epileptic seizures 
would fail to show changes in prolactin levels, and that a prolactin estimation 20 minutes following the seizure would be of value in helping differentiate epileptic from non-epileptic seizures. However, the situation regarding partial seizures was not clarified. We would here confirm that following generalised epilepsy with tonic-clonic neuromuscluar activity lasting longer than 30 seconds a rise in prolactin from baseline values, is highly suggestive of an epileptic seizure. If baseline values are within the normal range, then an elevation to greater than $1000 \mathrm{mu} / \mathrm{l}$ is seen following epileptic seizures. To clarify the situation further, a sample at one hour should show a return towards baseline values. If following such a seizure clinically no alteration of prolactin is seen then it is suggested that the patient has not had an epileptic seizure and an alternative diagnosis should be sought.

With partial seizures the same procedure may be adopted in those patients in whom alteration of consciousness is thought to have occurred. Here a cutoff point of $500 \mathrm{mu} / \mathrm{l}$ at 20 minutes with return to baseline value at one hour would be highly suggestive that the seizure event was epileptic. With simple partial seizures estimation of prolactin is unlikely to be of diagnostic value, and alternative means of distinguishing epileptic from non-epileptic attacks must be sought. From our studies alteration of LH levels could also be used, especially in the differential diagnosis of generalised seizures with tonic-clonic components. However the data are less clear-cut than the prolactin values at 20 minutes, and $\mathrm{LH}$ estimation may turn out to be of more value for estimation at a longer interval of time following the attack.

It is suggested that further observation of both anterior and possibly posterior pituitary hormone release following varieties of seizure types will be of value not only clinically in the diagnosis and classification of epilepsy, but theoretically from the point of view of understanding further the spread of neuronal activity during epileptic seizures. In addition, attempts to alter hormonal release following attacks using various drugs that block neurotransmitters may lead to a further understanding of the neurochemistry of epilepsy.

\section{References}

${ }^{1}$ Clemens JA, Shaar CJ, Kleber JW, Tandy WA. Reciprocal control by the preoptic area of $\mathrm{LH}$ and prolactin.
Exp Brain Res 1971;12:250-3.

${ }^{2}$ Ohman R, Walinder J, Balldin J. Prolactin response to ECT. Lancet 1976;2:936-7.

${ }^{3}$ O' Dea JPR, Gould D, Hallberg MA, Welland RC. Prolactin changes during electroconvulsive therapy. Am J Psychiat 1978;135:609-11.

4 Trimble MR. Serum prolactin in epilepsy and hysteria. Br Med J 1978;2:1682.

${ }^{5}$ Arato M, Erdo A, Kurcz M, Vermes I, Fekete M. Studies on the prolactin response induced by electroconvulsive therapy in schizophrenics. Acta Psychiat Scand 1980;61:239-44.

- Abbott RJ, Browning MCK, Davidson DLW. Serum prolactin and cortisol concentration after grand mal seizures. J Neurol Neurosurg Psychiatry 1980;43: 163-7.

${ }^{7}$ Hoppner RJE, Rentmeester TH, Arnoldussen W, Hulsmar J, Meijers CAM. The changes in serum prolactin level following partial and generalised seizures. Br J Clin Pract 1982;Suppl18:193-5.

${ }^{8}$ Collins WCJ, Lanigan O, Callaghan N. Plasma prolactin concentrations following epileptic and hysterical seizures. Br J Clin Pract 1982;Suppl18:191-2.

${ }^{9}$ Ryan RJ, Swanson DW, Fairman Cet al. Effect of ECT on FSH, LH, and growth hormone in man. J Clin Endocrinol Metab 1970;30:51-8.

${ }^{10}$ Vigas $M$, Nemeth S, Stowasserova N, Jurcovicova J. Effect of repeated electroconvulsive therapy on plasma LH and FSH in women. Endocrinol Exp (Bratisl) 1975;9:295-9.

$"$ Meldrum BS, Horton RW, Bloom SR, Butler J, Keenan J. Endocrine factors and glucose metabolism during prolonged seizures in baboon. Epilepsia 1979;20: 527-34.

${ }^{12}$ Noel GL, Suh HK, Stone JG, Frantz AG. Human Prolactin and Growth Hormone Release during Surgery and other Conditions of Stress. J Clin Endocrinol Metab 1972;35:840-51.

${ }^{13}$ Thorner MO, Login IS. Prolactin secretions as an index of brain dopaminergic function. Adv Biochem Psychopharmacol 1981;28:503-20.

${ }^{14}$ Heath RG. Psychosis and epilepsy: similarities and differences in the anatomic-physiologic substrate. $A d v$ Biol Psych 1982;8:106-16.

15 Jasper HH. Some physiological mechanisms involved in epileptic automatisms. Epilepsia 1964;5:1-20.

${ }^{16}$ Gastaut H. Clinical and electroencephalographical classification of epileptic seizures. Suppl Epilepsia 1969;10:S2-21.

${ }^{17}$ Penfield W. The Excitable Cortex in Conscious Man. Liverpool: Liverpool University Press, 1958.

${ }^{18}$ Commission on Classification and Terminology of the International League against Epilepsy. Proposal for Revised Clinical and Electroencephaolgraphic Classification of Epileptic Seizures. Epilepsia 1981;22:489-501. 